\section{Perspective}

J Prev Med Public Health 2021;54:218-219https://doi.org/10.3961/jpmph.21.081

pISSN 1975-8375 elSSN 2233-4521
Journal of

Preventive Medicine

\& Public Health

\title{
iDENTIfyme Informative Campaign: Raising Forensic Dental Identification Awareness in the Community
}

\author{
Emilio Nuzzolese \\ Section of Legal Medicine, Department of Public Health Sciences and Pediatrics, University of Turin, Turin, Italy
}

The identification of human remains can be performed visually through families and next-of-kin, but it is not advisable to rely only on visual recognition; instead, it is preferable to conduct a forensic comparison of antemortem and postmortem data for primary identifiers (fingerprints, DNA, and dental data). A dental autopsy is particularly valuable in the identification process of skeletonized, carbonized, saponified, and fragmented human remains. The principal challenge in the identification process is the search and collection of antemortem data. To this end, all dental information held on a missing person can represent a precious source of individualizing information that families should share with the police or investigating agencies after reporting a disappearance.

Key words: Human identification, Missing persons, Forensic odontology

The identification of human remains can be performed visually through the involvement of families and next-of-kin. Nevertheless, it is not advisable to rely only on visual recognition; instead, it is preferable to perform a forensic comparison of antemortem and postmortem data of primary identifiers (fingerprints, DNA, and dental data). A dental autopsy is particularly valuable in the identification process of skeletonized, carbonized, saponified, and fragmented human remains. The principal challenge in the identification process is the search and collection of antemortem data [1].

To this end, all dental information held on a missing person can represent a precious source of individualizing information that the family should share with the police or investigating agencies after reporting a disappearance. Nevertheless, in

Received: February 14, 2021 Accepted: March 25, 2021

Corresponding author: Emilio Nuzzolese

Section of Legal Medicine, Department of Public Health Sciences and Pediatrics, University of Turin Corso Galileo Galilei 22, Turin 10121, Italy E-mail: emilio.nuzzolese@unito.it

This is an Open Access article distributed under the terms of the Creative Commons Attribution Non-Commercial License (https://creativecommons.org/licenses/by$\mathrm{nc} / 4.0 / /$ which permits unrestricted non-commercial use, distribution, and reproduction in any medium, provided the original work is properly cited. some countries, forensic odontology is not always employed regularly for human identification for reasons including the lack of forensic odontologists. Simultaneously, the families of missing persons are often unaware that beyond the toothbrush, there are several other sources of dental information that might be available in the house and could be converted to useful forensic antemortem secondary identifiers, if reported to law enforcement agencies or missing persons non-governmental organizations. To raise awareness among the public and the families of missing persons on the importance of collecting all identifying primary and secondary dental data, in June 2019, the Human Identification Laboratory of the University of Turin launched an innovative informative campaign called "iDENTIfyme" using social media.

The aim of this campaign is to raise awareness on the collection of (antemortem) data related to the teeth and mouth of the missing person, by searching for portrait pictures depicting the smile or showing front teeth [2], old radiographs [3,4], dental devices such as sports mouthguards, bite plates for bruxism, bleaching trays, and old mobile orthodontic retainers. Families and relatives could still possess these sources of individualizing dental information, which risk being undervalued or not re- 
ported to the police. Portrait pictures or selfie pictures can show dental features such as diastema, rotated or wrongly positioned teeth, lip anomalies, recognizable fixed prosthetics, dental crown discolorations, and dental or cutis piercings [2,5].

The iDENTIfyme campaign raises awareness through an explanatory video helping families and relatives of missing individuals to recognize the above devices and to understand the importance of contacting their dentists to retrieve more dental information that could still be archived in a dental clinic, such as model casts showing palatal rugae [6], intraoral photographs, and prosthetics [7], as well as conformity certification of prosthetics and dental implant data [8].

The information campaign and the text have been translated, to date, into Arabic, Hindi, Italian, English, and Portuguese

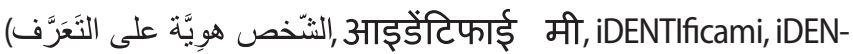
Tlfyme, and iDENTIficame, respectively). The video shows clear and simple images of all the dental devices and dental-related data that should be searched by the families and then eventually delivered to the police. The campaign is available for further translations to forensic odontologists of all nationalities.

This information can be converted into valuable forensic individualizing data and compared with the biological profile of the unidentified deceased, excluding the incompatible profiles of the missing and narrowing the list of compatible candidates with whom to conduct the comparison of antemortem and post-dental data to achieve a positive identification.

The informative campaign has also been distributed to missing persons national associations and media and has become a useful tool to place the importance of human identification (and, specifically, forensic odontology) in the spotlight of authorities in several countries where there is a need for more awareness and collaboration between families of the missing, police agencies, and forensic odontologists $[9,10]$.

\section{Ethics Statement}

This paper is a perspective, so it did not need ethical approval.

\section{CONFLICT OF INTEREST}

The author has no conflicts of interest associated with the material presented in this paper.

\section{FUNDING}

None.

\section{ACKNOWLEDGEMENTS}

None.

\section{AUTHOR CONTRIBUTIONS}

All work was done by EN.

\section{ORCID}

Emilio Nuzzolese https://orcid.org/0000-0001-9706-1106

\section{REFERENCES}

1. Nuzzolese E. Dental autopsy for the identification of missing persons. J Forensic Dent Sci 2018;10(1):50-54.

2. Nuzzolese E, Lupariello F, Di Vella G. Selfie identification app as a forensic tool for missing and unidentified persons. J Forensic Dent Sci 2018;10(2):75-78.

3. Angelakopoulos N, Franco A, Willems G, Fieuws S, Thevissen P. Clinically detectable dental identifiers observed in intra-oral photographs and extra-oral radiographs, validated for human identification purposes. J Forensic Sci 2017;62(4):900-906.

4. Silva RF, Picoli FF, Botelho TL, Resende RG, Franco A. Forensic identification of decomposed human body through comparison between ante-mortem and post-mortem CT images of frontal sinuses: case report. Acta Stomatol Croat 2017;51(3): 227-231.

5. Farrukh F, Mânica S. Fashion for a reason: oral jewellery to aid forensic odontology. J Forensic Leg Med 2019;66:38-43.

6. Rath R, Reginald BA. Palatal rugae: an effective marker in population differentiation. J Forensic Dent Sci 2014;6(1):46-50.

7. Chugh A, Narwal A. Oral mark in the application of an individual identification: from ashes to truth. J Forensic Dent Sci 2017; 9(2):51-55.

8. Mansour H, Sperhake JP, Bekaert B, Krebs O, Friedrich P, Fuhrmann $A$, et al. New aspects of dental implants and DNA technology in human identification. Forensic Sci Int 2019;302:109926.

9. Pandit S, Desai D, Jeergal P, Venkatesh S. Awareness of forensic odontology among police personnel: a new ray of hope in forensic odontology. J Forensic Dent Sci 2016;8(1):56.

10. Nuzzolese E. Integration of dentistry and forensic odontology for a structured identification system and border control. Forensic Sci Res 2021. doi: https://doi.org/10.1080/20961790.20 20.1842155 . 